\title{
Reconstruction of Post-Traumatic Bone Loss (BL) Members: Our Experience about 27 Cases
}

\author{
Moctar Traore ${ }^{*}$, Samba Kone², Maurice Kouame1, Raphael Dallo Gogoua1, Armand Yepie1, \\ Michel Anoumou' ${ }^{1}$, Guy Varango ${ }^{1}$ \\ ${ }^{1}$ Department of Orthopaedic Surgery and Traumatology, C.H.U de Treichville, Abidjan, Côte d'Ivoire \\ ${ }^{2}$ Department of Orthopaedic Surgery and Traumatology, C.H.U de Cocody, Abidjan, Côte d'Ivoire \\ Email: traore_moc@yahoo
}

Received 12 April 2016; accepted 4 June 2016; published 7 June 2016

Copyright (C) 2016 by authors and Scientific Research Publishing Inc.

This work is licensed under the Creative Commons Attribution International License (CC BY). http://creativecommons.org/licenses/by/4.0/

(c) $\underset{\mathrm{EY}}{\mathrm{Br}}$ Open Access

\section{Abstract}

The purpose of this study is to evaluate our results of treatment of post-traumatic bone defect of members through various bone reconstruction techniques. Patients and method: It is a retrospective study continues from January 2008 to December 2012. It involved 27 patients who had bone loss following trauma members. The average age of patients was 36.2 years. We noted a male predominance ( $22 \mathrm{men})$. The causes of injuries were dominated by accidents of public roads (12 cases) and ballistic trauma (14 cases). We noted one case of work accident. The BL was localized in 10 cases the tibia, femur in 4 cases, 8 cases in the humerus, 2 cases in the fibula, 1 case was located in the olecranon, 1 case at the distal radius and 1 case to the ball. All lesions were open fractures. After a mean of support for 3 days, we performed emergency around 19 associated with internal fixation (10 cases external fixation, internal fixation 9 cases), 8 single around. Bone reconstruction was performed secondarily in the majority of cases $(24$ cases). Only 4 reconstructions were performed in emergency. Reconstruction techniques were dominated by conventional grafts (24 cases) associated or not with the technique of induced membrane. Bone reconstruction techniques we used were as follows: 24 cases of traditional autografts and 3 cases of intertibio-fibular graft. After an average decline of $\mathbf{4 3 . 6}$ months, our patients were evaluated clinically (axis and limb length) and radiological (bone healing). Results: bone healing was achieved in 22 cases after a mean of 3.8 surgeries and an average of 14.8 months. Conclusion: the main principles governing the reconstruction of a defect are pre healing associated infection and repair soft tissue whenever it can do. The current trend is to hybridization of the reconstruction process of the great losses of substance by developing strategies based on both the deliberate shortening.

\footnotetext{
*Corresponding author.
}

How to cite this paper: Traore, M., Kone, S., Kouame, M., Gogoua, R.D., Yepie, A., Anoumou, M. and Varango, G. (2016) Reconstruction of Post-Traumatic Bone Loss (BL) Members: Our Experience about 27 Cases. Open Journal of Orthopedics, 6, 139-143. http://dx.doi.org/10.4236/ojo.2016.66021 


\section{Keywords}

\section{Bone Loss, Bone Reconstruction, Nonunion}

\section{Introduction}

The bone loss is a difficult problem in trauma mainly because of soft tissue lesions and the frequency of associated infections [1]. Schematically post-traumatic bone loss occur in 3 distinct circumstances: The BL is contemporary to the trauma: this is the result of a high-energy trauma that caused an open fracture of grade III of gustillo [2]. The BL result of iterative excision in the immediate aftermath of an open fracture. The BL is secondary to excision motivated by a subsequent bone infection in an infected closed fracture or nonunion suppurativa. The treatment of these BL fact calls for numerous reconstruction techniques such as conventional traditional grafts (autologous), bone transfers vascularized [3], bone mobilization techniques [4], the technique of induced membrane [5] well allografts and bone substitutes [6]. The implementations of some of these techniques required sometimes cumbersome logistical conditions. The objective of this study was to evaluate our results support post-traumatic bone loss by the methods of bone reconstruction that we were technically possible.

\section{Patients and Methods}

This is a retrospective study over a period of 5 years (from January 2010 to December 2014). Were included in this study in patients over 15 years, which showed bone loss of members from their emergency admission (we called primitive BL), or secondarily after excision of bone due to infection (secondary bone loss). All these patients had a bone reconstruction in emergency or later. Patients with secondary BL to tumor resection were deliberately excluded from the study. This allowed us to retain 27 patients with a mean age of 36.2 years. We noted a clear predominance of the male sex with 22 men (81.4\%) for 5 women (18.6\%). The etiologies of these BL were dominated by ballistic trauma with 14 cases (52\%) and traffic accidents 12 cases (45\%). A fall from a high place was originally a BL in 1 patient. The BL was predominantly localized in the lower limb with 17 cases (62.96\%) with 10 cases in the tibia (37.4\% including 09 diaphyseal, 1 distal epiphysis), 4 cases the femur (14.81\%) 2 cases the fibula and 1 case to the ball. The upper limb was involved in 10 cases (37.04\% including 8 cases in the humerus, 1 case in the ulna (olecranon), 1 case at the distal radius). Table 1 shows the different locations of the BL.

All lesions were open fractures. According to the classification of Cauchoix and Duparc [7], there was a predominance of type II with 15 cases (55.5\%) and type III with 8 cases (29.6\%), 2 with vascular injury. Only 04 open fractures were Type I (14.8\%).

After a mean of support for 3 days, all patients underwent debridement emergency. This debridement was associated with internal fixation in 19 cases (10 cases external fixation, internal fixation 9 cases), 08 single around. The majority of bone reconstructions (23 cases) was made secondarily by autologous transplants in the absence of clinical and biological signs of infection. Only 04 reconstructions were performed in emergency by corticocancellous bone graft iliac which 1 in the femur, the tibia 1,1 to the olecranon and 1 at the distal radius. The technique of the induced membrane was used in 14 cases (Figure 1). This technique, described by Masquelet [5] allows the reconstruction of large bone loss on septic focus. It is done in 2 stages: a first time of resection of necrotic tissue, the establishment of an acrylic cement spacer with antibiotics, mechanical stabilization of the fracture by external fixator and skin-muscle coverage. This time training around the spacer, rich in active growth factors membrane on the proliferation and cell differentiation The second time achieved 4 to 6 weeks again later involves the removal of the spacer after opening the membrane and the contribution of cancellous graft. So we

Table 1. Location of the BL according to the bone.

\begin{tabular}{ccccccccc}
\hline Seat & Humerus & Ulna & Radius & Fémur & Patela & Tibia & Fibula & Total \\
\hline Number & 08 & 01 & 01 & 04 & 01 & 10 & 02 \\
Percentage & $29.6 \%$ & $3.7 \%$ & $3.7 \%$ & $14.8 \%$ & $3.7 \%$ & $37.1 \%$ & $7.4 \%$ & 100 \\
\hline
\end{tabular}




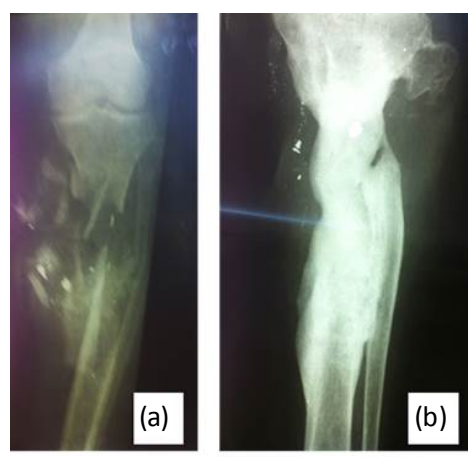

Figure 1. Tibial bone loss treated by inter-tibiofibular graft (ITFG) (a) initial lesion. (b) consolidation after graft.

used this technique in 14 of our patients who had sepsis after the initial debridement. Inter-tibiofibula graft (ITFG) [8] was necessary to achieve consolidation in 3 patients (Figure 2). The graft donor site was dominated by the iliac crest 26 cases against one taken at the expense of the anterior tibial tuberosity.

A flap of skin or muscle fasciocutaneous cover was necessary for the repair of soft tissue in all 8 patients with type III open fractures; 4 with shreds of the soleus muscle, 2 fasciocutaneous tattered shreds hamstrings and 2 internal tibialis muscle. Table 2 shows the distribution of the BL according to the used reconstruction technique. After an average decline of 43.6 months, our patients were evaluated clinically (getting skin healing, indolence, axis and limb length) and radiologically (obtaining bone healing).

\section{Results}

The evolution after the first bone graft was marked by bone consolidation immediately in 6 patients. The change was made to nonunion in the other 21 patients, including 7 infected (septic nonunion) and 14 uninfected (aseptic nonunion). An iterative surgery was necessary in these patients. Averaged 3.8 surgical procedures were performed in our patients. Finally, 22 patients (81.4\%) had bone healing after a mean of 14.8 months. Table 3 show the results based on the location of the bone defect. However, we noted a shortening of the lower limb of less than $2 \mathrm{~cm}$ in 3 patients and 2 cases of shortening of more than $4 \mathrm{~cm}$ associated with important trophic disorders in the leg. The other 05 patients or $18.6 \%$ were unable to obtain consolidation. These were all patients who had open fractures type III. Among them, 2 have been cut to massive infection in his leg. The other 3 are still septic nonunion (1 case in the leg, the femur 1 case and 1 case in the humerus).

\section{Discussion}

Post-traumatic BL are usually secondary to high energy trauma and bone loss is usually associated with extensive soft tissue devascularization, factors of poor prognosis as well as infection and exposure of the home fracture. Our poor results were observed with the exposed fractures type III (05 of 08). With this type of injury, the therapeutic approach is far from unequivocal. Most authors: Christian [9] Cierny [10] Jorgenson [11] Small [12], Thakur [13] Yaremchuk [14] advocate a secondary bone grafting 2 - 9 weeks after the coverage. However, when this bone graft is done secondarily, it can ask a technical problem of surgical approach because of the scar condition of the leg, the eventual realization of a free flap, which could compromise the micro-sutures or a vascular graft [12]. Moreover, the lack of flexibility of the skin can make it difficult to suture skin graft level with a risk of necrosis. Giarbuio et al. [15] when to advocate them in an aggressive emergency treatment with internal fixation of the fracture by intramedullary nailing locked fracture coverage by a pedicled or free flap and autologous iliac corticocancellous. This technique significantly improves the final result by reducing complications, consolidation time and enabling earlier socio-professional rehabilitation. Unfortunately, the delay in the care of our patients and the lack of logistic conditions made it difficult to implement this strategy. We stay in our traditional support which is performed in two steps: trimming associated with external fixation initially then cover and flap reconstruction in a second time.

We performed traditional autologous cortico-cancellous iliac associated with membrane technology induced infections. It seems to work well as 12 of the 14 patients who received $85.7 \%$ of this technique have obtained 

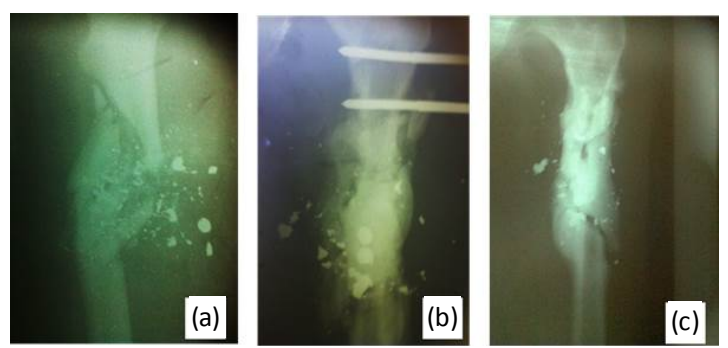

Figure 2. Femoral bone loss treated by the technique of induced membrane (a) Initial lésion (b) spacer (c) consolidation after graft.

Table 2. Distribution of the BL according to reconstruction technique.

\begin{tabular}{cccc}
\hline technique & Induced membrane & ITFG & Iliac traditional graft \\
\hline number & 14 & 03 & 10 \\
\hline
\end{tabular}

Table 3. Results based on the location of the bone defect.

\begin{tabular}{ccccccccc}
\hline Seat & Humérus & Ulna & Radius & Fémur & Patela & Tibia & Fibula & Total \\
\hline Number & $08(29.6)$ & $01(03.7)$ & $01(03.7)$ & $04(14.8)$ & $01(03.7)$ & $10(37.1)$ & $02(7.4)$ & 27 \\
Consolidation & 07 & 01 & 01 & 03 & 01 & 08 & 01 & 22 \\
\hline
\end{tabular}

bone healing. These good results were observed in several other authors who used the same technique Masquelet [16] with $88.57 \%$ of consolidation after a period of 14.4 months, Karger [17] obtained $90 \%$ of good results after a mean 14.4 months. the transplant intertibiofibulaire [8] was we needed for the reconstruction of 3 major loss of bone in the shin with $100 \%$ consolidation. According Masquelet AC, this technique remains the cornerstone of any reconstruction extended to tibial section, with even better results when combined with the induced membrane.

Some techniques are used for the reconstruction of the great loss of substance: vascularized bone transfer such as transfer of vascularized fibula [3]-[18], the bone transport technique using segmental material Ilizarov [4], allografts and homograft bank and bone substitutes [6]. These different techniques that have proved their effectiveness especially in the reconstruction of large bone defects. We did not use any of these techniques by lack of logistics condition.

\section{Conclusion}

The main principles governing the reconstruction of a defect are pre healing associated infection and repair soft tissue whenever it can do. The current trend is to hybridization of the reconstruction process of the great losses of substance by developing strategies based on both the deliberate shortening, all forms of traditional transplants, bone mobilization and induced membrane. The technically induced membrane and GITP remain usable techniques in our terms of exercise mainly because of their ease of implementation and good results.

\section{Limits of the Study}

This study is limited by its retrospective nature, the small sample size and the impossibility of achieving other bone reconstruction techniques. A case-control study on a larger sample will be necessary for future study.

\section{Conflict of Interests}

The authors declare no conflict of interest

\section{Author's Contributions}

This study was approved by the local ethics committee and all the authors contributed to the writing of this 
manuscript, and had read and approved the final version.

\section{References}

[1] Masquelet, A.C., Sales De Gauzy, S., Bauer, T., Fabre, A., Fitoussi, F., Hannouche, D., Jouve, J. and Karger, C., All The SOFCOT (2012) Reconstruction Loss of Bone Substances Diaphyseal Traumatic Origin: Strategies, Recommendations, Perspectives. Revue de Chirurgie Orthopedique et Traumatologique, 98, 94-103.

[2] Gustillo, R.B., Mendoza, R.M. and William, D.N. (1984). Problem in the Management of Type III (Sever) Open Fractures: A New Classification of Type III Open Fractures. Journal of Trauma-Injury Infection \& Critical Care, 24, 742746. http://dx.doi.org/10.1097/00005373-198408000-00009

[3] Taylor, G.I., Miller, G.D. and Ham, F.J. (1975) The Free Vascularized Bone Graft a Clinical Extension of Microvascular Techniques. Plastic \& Reconstructive Surgery, 55, 533-544. http://dx.doi.org/10.1097/00006534-197505000-00002

[4] Rigal, S., Merloz, P., Le Nen, D., Mathevon, H., Masquelet, A.C. and Masquelet SOFCOT (2012) Technique Mobilization Bone in Bony Defects Caused by Trauma. Revue de Chirurgie Orthopedique et Traumatologique, 98, 8893.

[5] Masquelet, A.C., et al. (2000) Reconstruction of the Long Bone by the Induced Membrane and Spongy Autograft. Annales de Chirurgie Plastique Esthétique, 45, 346-353.

[6] Vastel, L. (2010) Allograft Bone and Tissue Banks. Medico-Surgical Encyclopedia: Musculoskeletal, 14-015-A-10.

[7] Cauchoix, J., Duparc, J. and Boulez, P. (1957) Treatment of Open Fractures of the Leg. Memory of The Academy of Surgery Paris, 83, 811-822.

[8] Fitoussi, F., Masquelet, A.C., Rigal, S., Bauert, P.A. and Fabre, A. (2012) Fibular Graft-Intertibio in Treating Bone Loss Diaphyseal Tibial. Revue de Chirurgie Orthopedique et Traumatologique, 98, 192-198.

[9] Christian, E.P., Bosse, M.J. and Robb, G. (1989) Reconstruction of Large Diaphyseal Defects, without Free Fibular Transfer, in Grade IIIB Tibial Fractures. The Journal of Bone and Joint Surgery. American Volume, 71, 994-1004.

[10] Cierny, G., Byrd, H.S. and Jones, R.E. (1983) Primary versus Delayed Soft Tissue Coverage for Severe Open Tibial Fractures. Clinical Orthopaedics and Related Research, 178, 54-63. http://dx.doi.org/10.1097/00003086-198309000-00008

[11] Jorgenson, D.S. and Antoine, G.A. (1995) Advances in the Treatment of Lower Extremity Wounds Applied to Military Casualties. Annals of Plastic Surgery, 34, 298-303. http://dx.doi.org/10.1097/00000637-199503000-00013

[12] Small, J.O. and Mollan, A.B. (1992). Management of Soft Tissues in Open Tibial Fractures. British Journal of Plastic Surgery, 45, 571-577. http://dx.doi.org/10.1016/0007-1226(92)90022-P

[13] Thakur, A.J. and Patankar, J. (1991) Treatment by Uniplanar External Fixation and Early Bone Grafting. The Journal of Bone and Joint Surgery. British Volume, 73, 448-451.

[14] Yaremchuk, M.J., Brumback, R.J., Manson, P.N., Burgess, A.R., Poka, A. and Weiland, A.J. (1987) Acute and Definitive Management of Traumatic Osteocutaneous Defects of the Lower Extremity. Plastic \& Reconstructive Surgery, 80, 1-12. http://dx.doi.org/10.1097/00006534-198707000-00001

[15] Guarbuio, P. and Tropet, Y. (1999) Open Leg Fractures Type III with Bone Loss: Interest Bone Graft Contemporary Urgency of the Internal Skeletal Fixation and Coverage. Maîtrise Orthopédique No. 87.

[16] Masquelet, A.C., Begue, T., Muller, G.P., et al. (2001) Long Bone Reconstruction Using an Induced Membrane and Cancellous Autograft a Series of 35 Cases. The Journal of Bone and Joint Surgery. British Volume, 838, suppl I-41.

[17] Karger, C., Kishi, T., Schneider, L., Fitoussi, F. and Masquelet, A.C. (2012) Treatment of Posttraumatic Bone Defect by the Induced Membrane Technique. Orthopaedics and Traumatology: Surgery and Research, 98, 97-102. http://dx.doi.org/10.1016/j.otsr.2011.11.001

[18] The Neud, Dubrana, F., Hu, W., Prud'homme, M. and Lefevre, C. (2002) Fibula Vascularized. Techniques, Indications in Orthopedics and Traumatology. Ecycl Med Chir (scientific and medical publishing Elsevier SAS, Paris), Technical chirurgicales-Orthopédie-Traumatology, 44-040, p. 10. 